

\title{
INTERACTION BETWEEN THE ECONOMIC GROWTH AND THE CONSTRUCTION INDUSTRY: A TIME SERIES ANALYSIS ON TURKEY (2000-2012)
}

\author{
Ph. D. Bilal Karg1
}

\section{INTRODUCTION}

Growth and progress sustain each other. While theoretically they can relatively grow apart in the long run, they have to complete on another to develop humane living conditions. While for the developed economies the continuation of growth and its effect on the improvement of the life quality of society are aimed; the production of capital stock that is necessary for the growth in the progress theory should be concentrated on. Economic growth is defined as the increase of total output and to this end gross domestic product (GDP) data which is the indicator of everyone's total income, is used (Mankiw, 2010:191). The factors that affect the increase of total output according to Solow (1956) are the accumulation of capital, technological advancements, and the rise in labor-force. Economic growth is used generally about the improvement of humane living conditions and specifically for the economies where the accumulation of capital is not sufficient enough and the developing economies. Accumulation of capital is a prerequisite for the geometric growth of economy which was dubbed as “Take-off” by Rostow (1960). The construction industry consists of every kind of building that is necessary for the physical needs of humans from dwelling to the structures that meet the economic need of humankind like roads, bridges, and harbors. In the developed world, especially in the aftermath of the World War II, the construction industry had become a crucial economy policy to rebuild Europe, its housing and infrastructure (Lopes, 2011).The construction industry makes a hefty contribution to the economy as a whole as well as having an extensive connection to the other sectors of the economy (Khan, 2008:281). While modern life keeps on recruiting people to the cities, the construction industry try to maintain an array of sustainable qualities. Concordantly, Bon and Hutchison (2000) emphasize that the construction industry receives input from all manners of sectors mesoeconomically and underlines the construction industry's sustainability as an assembly tier of this wide spectrum (For a general chart of these relationships see Wibowo, 2009).

"The inter-industry relationship" term was first coined by Hirschman (1958). The forward and backward linkages of the construction industry are quite powerful. That is why it is closely related to the economic growth. In the traditional Keynesian economy, investments -at least construction investments- play a role in the total demand and the sustainability of the economic growth in the short run (Wigren and Wilhelmsson, 2007:339). On the other hand, the construction industry is a labor-intensive industry when compared to others (Hillebrandt, 2000; Giang ve Pheng, 2011).

There are two fundamental hypotheses regarding the analysis of the relationship between the economic growth and the construction industry. The first one is as follows: "As the economy develops the slice that is occupied by the construction industry in the GDP decreases." The second one is that "the parcel of construction industry in the GDP of developing countries increases." Additionally the third hypothesis, " when talking about the periods of crisis in all country groups, the percent of construction industry in the GDP goes down in recession while it goes up in the aftermath of recession" can be tested. Therefore it suggests a compliance with the general trend in the economy. But when these relationships are tested in different countries and in different country groups, the outcomes of the studies can both overlap with these hypotheses or contradict them.

Interaction between the economic growth and the construction Industry:A Time Series Analysis On Turkey (2000-2012) 


\section{Construction Sector and Turkey}

The empirical studies conducted on the developing countries have indicated that the construction industries in the said economies grow continuously. In the countries of this status, the constructions consist of a wide variety from industrial buildings to dwellings, from energy plants to state infrastructure investments. As an economy in this category, especially after 1980's the construction industry in Turkey has been continuously growing and developing. When tackling the period after 2000, the increase of GDP can be detected in the construction industry. It can also be detected that both the state's and the private sector's expenditure for construction increase. The economic crisis that took place in the beginning of 2000's had a deep impact on all sectors including the banking industry and the construction industry. The economy that was contracted 3.35\% year-on-year basis in 1999 had shown a 6.73\% growth in 2000 and again went through a deeper trauma with a $5.68 \%$ contraction in 2001. After the political pull these traumas in succession created, there was a growth trend up until 2008. In the same period the consumer price index relatively reached a stability compared with the previous periods and hovered around the $8-10 \%$ year-on-year basis. Therefore in the period at hand, economy was relatively stable.

The construction industry is handled as having three fundamental components: New buildings, renovations and materials. For each of these components there is plenty of input. Input for the construction industry consists of many different materials, some supplied from Turkey and some imported.

In Turkish economy the construction materials are exported to 200 countries (the biggest markets are Iraq, Germany, UAE, Great Britain and USA) and the biggest percent consists of iron-steel products. While the industry's worth was 4.1 billion US dollars in 2002, the export volume in 2011 was 19.7 billion US dollars. The industry lived through its biggest fluctuation in 2009 and contracted $33 \%$ compared to 2008, its volume dropped down to 15.7 billion US dollars. In the importation of construction materials, the first is iron-steel with 2.2 billion US dollars; the second is cooling and heating units with 1.1 billion US dollars and third is electrical equipment with 1.1 billion US dollars. While Turkey imports construction materials from 176 countries, the leading commerce partners of Turkish economy are China, Germany, Italy and France. This continuously growing industry's 2011 volume was 8.8 billion US dollars (Data: TUIK). According to the data, Turkish economy in 2011 has a surplus in the construction material foreign trade.

In 2010, the leader countries in the exportation of construction materials were USA with a volume of 70.8 billion US dollars; Germany with a volume of 45.7 billion US dollars; and China with a volume of 33.1 billion US dollars making up the first three. Turkey had been $30^{\text {th }}$ in this ranking. In the importation of construction materials the first three countries were as follows: China with a volume of 109.5 billion US dollars; Germany with a volume of 86.5 billion US dollars; Italy with a volume of 51.8 billion US dollars. Turkey was the $7^{\text {th }}$ in the importation ranking (Data: Trademap).

Therefore because when the construction industry livens up, the material industry should also perk up, an effective improvement in the economy can be detected. Therefore the construction industry has a pull force/ drag force for the material industry. To put in other words, the construction industry creates indirect employment together with the direct employment in the production of the buildings. From 2009(1) to 2012(3), the employment in the construction industry had increased $78.71 \%$.

The relationship of the construction industry that consists of primary expenses of cement, iron-steel, paint, other stones, timber, glass, ceramic and plastic materials (Classification: TUIK) and the GDP can be 
observed in Graph-1 (Appendix-1). From 2002(1) to 2008(3) the growth continued even if there were slight fluctuations and a peak was reached. With the global recession Turkey's economy commenced a period of contraction after 2008(4). Still in the 2012(3), the GDP in the period of 2008(3) couldn't be reached. In this period up until 2008(3), the construction industry followed the same route as the GDP and it increased continuously. After the contraction in the 2008(4), the peak in 2008(3) was achieved once in 2011(2) but still the stability prior to 2008(3) couldn't be attained.

The relationship between the construction industry and the GDP is shown in the ratio change in Graph-2 (in another illustration Graph-3. Appendix-2 and Appendix-3). From the 51 quarters in the period, in 31 quarters the construction industry shows a higher growth ratio than the GDP. At the same time, the two variables moved in the same direction in 35 quarters. The best quarterly performance of GDP is $32.37 \%$ in 2003(3) (in the same quarter the construction industry grew 21.03\%) and the worst quarterly performance of GDP is $-30,20 \%$ (in the same quarter construction industry contracted by 28,53\%). While the construction industry exhibited its best quarterly performance in 2000(2) with a growth of 41,63\% (in the same quarter GDP was 6,10\%,) and the worst quarterly performance of construction industry was in 2008(4) when it contracted 28,53\% (in the same quarter GDP was $-30,20 \%)$. In short the construction industry is highly susceptible to the GDP. The fluctuations in the GDP and the construction industry overlap. These relationships can be analyzed more efficiently with an econometric model.

\section{Literature Review}

The models pertaining to the relationship between economic development and the growth of construction industry are generally created without taking into account (1) the development level of the countries (2) the general trend of the economy (3) temporal relations (the time span between the beginning and the end of construction) and different relations are made apparent. This study focuses on the first two models.

In developed economies, while construction of residences and/or infrastructure and other building investments have direct effects on the investments, it is also purported that these have indirect effects on the economic growth. In Western Europe, while the volume of the construction industry in the GDP in the year 1980 was $10 \%$, in 2004 this percentage dropped to 7\%. (Wigren and Wilhelmsson, 2007:449). On the other hand, Pietroforte and Gregori, in their study of the developed six (Australia, Canada, Denmark, France, Germany and Holland), reached the conclusion that the role of the construction industry in the national economies of these countries have decreased.

Lopes (2003), in a study on Portuguese economy, arrived at the conclusion that in the long run the construction industry in this country grows steadily. However, in his analysis of the Portuguese economy, he argues that as the development level increases, the role of construction industry in the economic growth tends to decrease. Lopes, Oliveira and Abreu (2011), emphasize the significance of the construction industry in socioeconomic growth level, in other words, development level and purported that during the first phases of economic development the per capita income level and the construction industry manifest a parallel tendency towards increase. As the countries reach a certain level of growth, the development of construction industry takes place at a slower pace than the economic development.

Dlamini (2012) has concluded that there is not a strong relationship between the construction industry and the economic growth. He also underlines that in the short run, the construction industry has a potential of positive impact on economic growth but it's an important component in the investment programs in developing economies

Interaction between the economic growth and the construction Industry:A Time Series Analysis On Turkey (2000-2012) 
like South Africa. In their study of the Indian economy Mallick and Mahalik (2008:381) have concluded that the growth rate of the construction industry is an important marker on the real growth of economy. Additionally they have reached the conclusion that with the growth of employment in the construction industry the total output of economy increases.

In his study, Bon (1992) reached the conclusion that the percentage of the construction industry in the national production creases in the early period of development in economies, yet in the long run, its share in the national product decreases proportionally and with certainty. In the study of Lopes, Ruddock and Ribeiro (2002:158-159) which was conducted on 16 African economies, the share of the construction industry in the GDP and the economic growth only exhibits a consistent relationship in times of crisis. According to them in the first instances of improvement in the aftermath of an economic recession, the GDP increases faster; whereas in the periods of sustainable economic growth and development, the same general growth rates can be detected.

The construction industry is vastly affected by the economic growth trends and the fluctuations in these trends. Because the process of the economic growth is closely related especially to the sufficiency of the public infrastructure investments even if there are fluctuations (Giang and Pheng, 2011:123). These relationships can be summarized in three scenarios: a) when the infrastructure was previously built, it is enough for the growth; b) if the infrastructure had been previously realized in an exorbitant style, there would be an unexpected fall in the economy; c) when an unexpected economic growth happens, the infrastructure would be inefficient to support the growth.

Spence and Mulligan (1995:291) point out that because of the space it use sand its input, the construction industry has an intense relationship with nature, therefore the input should be diminished and the sources should be utilized in a productive manner. In their study for 34 countries, Jin and Lu (2002) have concluded that there is a nonlinear relationship between the GDP and the construction output. In their study on the Hong Kong economy Yiu, Lu and Jin (2010:344) have reached the conclusion that between the GDP and the growth of the construction industry, there is Granger causality.

\section{Data and Analysis}

These variables have been selected to analyze the relationship between the construction industry and the economic growth: 1- GDP (gdp), 2- Gross fixed capital formation (gfcf), 3- Inflation (cpi), 4- The construction expenditure in the gross domestic product-Public Sector (cegdpps), 5- The construction expenditure in the gross domestic product-Private Sector (cegdpprs) 6- Istanbul Stock Exchange National 100 Index (imkb100), 7- Istanbul Stock Exchange non-metal minerals index (xtast), 8- The construction expenditure in the gross domestic productTotal (cegdptot),

The data concerning all the variables had been acquired from the Electronic Data Distribution System (EDDS) of the Central Bank of the Republic of Turkey (CBRT). These are the quarterly data ( $\mathrm{n}=51)$ pertaining to the 2000:01-2012:03 period, and it was accepted as the then current value of the aforementioned period and it was converted to US dollars using the exchange rate of the said period. The graphs were prepared in Excel, and the analysis was calculated by the Eviews software. A four-step analysis process was pursued. First, the variables were subjected to the correlation analysis (Table-1. Appendix-4) with the level values. In the second step, the unit root analysis of the series was done by Dickey-Fuller Test (1979) (Table-3. Appendix-6). After using the first difference, it was re-subjected to the correlation analysis (Table-2. Appendix-5). In the third step, the stationary series was subjected to the Granger Causality Test (1969) (Table-4. Appendix-7). In the fourth and final step, the

Interaction between the economic growth and the construction Industry:A Time Series Analysis On Turkey (2000-2012) 
regression models (Table-5. Appendix-8; Table-6. Appendix-9; Table-7. Appendix-10; Table-8. Appendix 11) which are below $\left(5^{\text {th }}, 6^{\text {th }}, 7^{\text {th }}\right.$ and $8^{\text {th }}$ equations $)$ were tested.

These are the regression models that were tested:

$$
\begin{aligned}
& i m k b 100=b_{0}+b_{1} x t a s t+u \\
& g f c f=b_{0}+b_{1} g d p+b_{2} c p i+b_{3} c e g d p p s+b_{4} c e g d p p r s+u \\
& g d p=b_{0}+b_{1} g f c f+b_{2} c e g d p p s+b_{3} c e g d p p r s+b_{4} x t a s t+u \\
& x t a s t=b_{0}+b_{1} g d p+b_{2} g f f f+b_{3} i m k b 100+b_{4} c e g d p p s+b_{4} c e g d p p r s+u
\end{aligned}
$$

In the process of this analysis, the relationship between the economic growth of Turkey and the fluctuations of the economy, and the construction industry is tackled. At the same time, this study tried to tackle the influences that affect the non-metal minerals index (XTAST) which is observed to be the indicator of the construction industry. Additionally in this paper, the efficiency of the public and the private construction expenditure in the GDP is tried to be laid down reciprocally and the efficiency of the gross fixed capital formation which also includes the construction industry is tried to be explicated.

\section{Findings}

By way of analyzing the outcome of the correlations in respect to the level values of the variables (Table-1. Appendix-4), a strong correlation between all the variables except the GDP and the inflation can be detected. Inflation has a negative moderate correlation with all the other variables. A positive high correlation was detected between all the variables except inflation. Yet because the series is not stationary, the correlations were calculated by applying first differences.

In respect to the correlation (Table-2. Appendix-5) to the first difference, there is a strong correlation (0.658037) between the GDP and the overall construction expenditure. Yet the private sector's construction expenditure $(0.280526)$ has a stronger correlation with the GDP than the public sector's construction expenditure (0.671524). While the GDP has such a strong relationship with the construction expenditure, the construction sector doesn't exhibit a correlational relationship with the inflation (0.008394). Additionally the sector does not exhibit a remarkable correlational relationship with the IMKB100. But a strong correlational relationship between the fixed capital formation and the overall construction sector $(0.890529)$ has been detected. The relationship has a stronger correlation for the private sector (0.70807) than it has for the public sector (0.535929). Finally there is a strong correlation (0.747157) between the overall construction sector and the private sector's construction expenditure. Again there is a strong correlation (0.89927) between the IMKB100 and the non-metal minerals index.

With the results of the ADF test (Table-3. Appendix-6) that the series were subjected to, it had been derived that the series were not stationary and that they included unit roots. The test statistics (ADF) that were calculated in respect to the levels of the variables showed that while the inflation data were stationary, the other variables contained unit roots. When the first difference was applied to the series $(\Delta)$, all series became stationary. Moreover the $\mathrm{R}^{2}$ values for all the variables have been obtained were lesser than Durbin-Watson (dw) test statistics.

Interaction between the economic growth and the construction Industry:A Time Series Analysis On Turkey (2000-2012) 
The series which were rendered stationary by applying the first difference was then subjected to the Granger Causality Test and according to the test results (Table-4. Appendix-7) with a confidence level of 5\%, it is detected that overall there are 23 causality relationships but not between each and every variable. All variables are in a causality relationship with at least one other variable. The variables that had the most causality relationships with other variables are as follows: gfcf (5 variables), imkb100 (4 variables), and xtast (4 variables). The mutual causality relationship happened between the "cegdpprs-gdp" and the "cegdptot-cegdpprs" causality pairs.

At the final stage, four regression models were tested. Because in each and every regression model the $\mathrm{dw}$ statistics are more than the $\mathrm{R}^{2}$ value $\left(\mathrm{dw}>\mathrm{R}^{2}\right)$ the regressions are not fake regressions and they do have a meaning. Especially where the imkb100 (0.804700), gfcf (0.780628) and xtast (0.873179) are "dependent variables," it is detected that the regressions have a rather high $\mathrm{R}^{2}$ value. For the other variable gdp (0.521584), a relatively lower $\mathrm{R}^{2}$ value was calculated.

\section{Conclusion}

In Turkish economy the construction industry exhibits the same distinctive feature as it did in the studies conducted on the economies of other developing countries and the process of growth supports the construction industry. The susceptibility of the construction industry to the GDP exhibits the private sector's construction investments and especially the public sector expenditure on the infrastructure move in conjunction with the growth process. The increase in the public sector's infrastructure expenditure is expected in the developing countries. The susceptibility of the construction industry towards the GDP indicates that the growth in this industry is not excrescent. Especially the relationship between the GDP and the construction industry after 2008 supports this thesis. Yet even if the public sector's expenditure weighs more in the overall expenditure of the construction industry the private sector's insufficiency should not be overlooked.

At the same time the construction industry has exhibited a negative susceptibility towards inflation.

In respect of stock market, the construction industry has a strong relationship with the IMKB100 index. Correlation (Level=0.909787; First Difference=0.89927) relationship informs us of the strength of the forwardbackward linkages of the sector. 


\section{Bibliography}

1. Bon, R (1992), 'The Future of International Construction': Secular Patterns Growth and Decline', Habitat International, Vol.16, 3, pp.119-128.

2. Dickey, D. A., Fuller, W. A., (1979). "Distribution of the Estimators of Autoregressive Time Series with a Unit Root", Journal of the American Statistical Association, Vol.74, pp.427-431.

3. Dlamini, S. (2012). "Relationship of Construction Sector to Economic Growth", International Congress on Construction Management, Canada.

4. Giang, T. H. Ve Pheng, L. S. (2011). "Role of Construction in Economic Development: Review of Key Concepts in The Past 40 Years", Habitat International (35), pp.118-125.

5. Granger, C. W. J., (1969). "Investigating Causal Relations by Econometric Models and Cross-Spectral Methods", Econometrica, Vol.37, No.3, pp.424-438.

6. Hillebrandt, P. M. (2000). Economic Theory and The Construction Industry (3rd ed.). Basingstoke, Hampshire: Macmillan.

7. Hirschman, A.O. (1958). The Strategy of Economic Development, Yale University Press, New Haven, CT.

8. Jin, W, Lu, X. and He Y. (2003). "A Regression Model of The Growth Path of Construction Industry (in Chinese)", Chinese Civil Engineering Journal Vol. 36(3), pp.105-109.

9. Khan, R. A. (2008). "Role of Construction Sector in Economic Growth: Emprical Evidence from Pakistan Ekonomy", First International Conference on Construction In Developing Countries. Pakistan. pp.279-290.

10. Lopes, J (2003) "The Relationship Between Construction Outputs and GDP: Long-Run Trends from Portugal", In: Greenwood, D J (Ed.), 19th Annual ARCOM Conference, 3-5 September 2003, University of Brighton. Association of Researchers in Construction Management, Vol.1, pp.309-317.

11. Lopes, J. (2011). "Construction and Economic Growth in Developing Countries of Africa: Evidence from Data of The Last Thirty Years”, CIB World Building Congress. Salford-Reino Unido.

Interaction between the economic growth and the construction Industry:A Time Series Analysis On Turkey (2000-2012) 
12. Lopes,J. P., Oliveira R. A. ve Abreu, M. I. (2011). The Construction Industry and the Challenges of the Millennium Development Goal. Management and Innovation for a Sustainable Built Environment, Amsterdam.

13. Lopes, J. Ruddock L. \& Ribeiro F. R. (2002): "Investment in Construction and Economic Growth in Developing Countries”, Building Research \& Information, Vol.30:3, pp.152-159.

14. Mallick, H. ve Mahalik, M. K. (2010). "Constructing the Economy: The Role of Construction Sector in India's Growth”, Journal of Real Estate Finance and Economics. Vol.40, pp.368-384.

15. Mankiw, N. G. (2010). Macroeconomics. Worth Publishers, New York.

16. Pietroforte R., Gregori T. (2003). “An Input-Output Analysis of The Construction Sector in Highly Developed Economies”, Construction Management and Economics, Vol.21:3, pp.319-327.

17. Ranko Bon \& Keith Hutchinson (2000). "Sustainable Construction: Some Economic Challenges", Building Research \& Information, Vol.28:5-6, pp.310-314.

18. Rostow, W. W. (1960). The Stages of Economic Growth: A Non-Communist Manifesto. Cambridge University Press, Cambridge.

19. Solow, R. (1956). "A Contribution to the Theory of Economic Growth", Quarterly Journal of Economics, Vol.1 No.70. pp.65-94.

20. Spence R. ve Mulligan, H. (1995). "Sustainable Development and the Construction Industry", Habitat International, Vol.19, No.3. pp.279-292.

21. Wibowo, M. A. (2009). "The Contribution of The Construction Industry into the Economy: A Systemic Approach", International Seminar, CIB 107, UTM, Malaysia.

22. Yiu, Lu ve Jin (2010). "A longitudinal Analysis on The Relationship Between Construction Output and GDP in Hong Kong”, Construction Management and Economics, Vol.22:4, pp.339-345.

Interaction between the economic growth and the construction Industry:A Time Series Analysis On Turkey (2000-2012) 


\section{APPENDIXES}

\section{Appendix: 1}

Graph 1: GDP and The Construction Expenditure in The Gross Domestic Product-

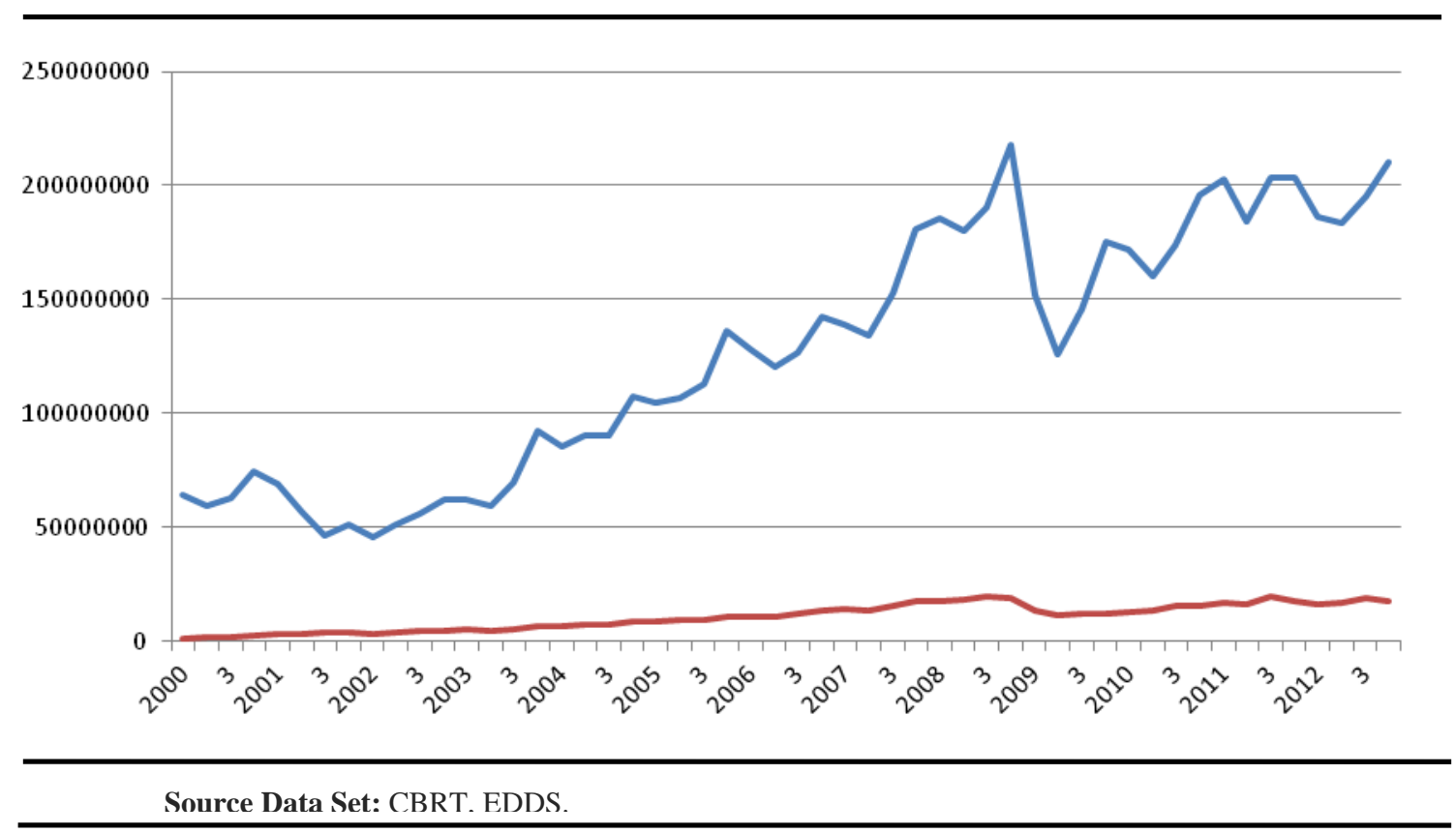

\section{Appendix: 2}

Graph 2: GDP and The Construction Expenditure in The Gross Domestic Product-Total (Rate)

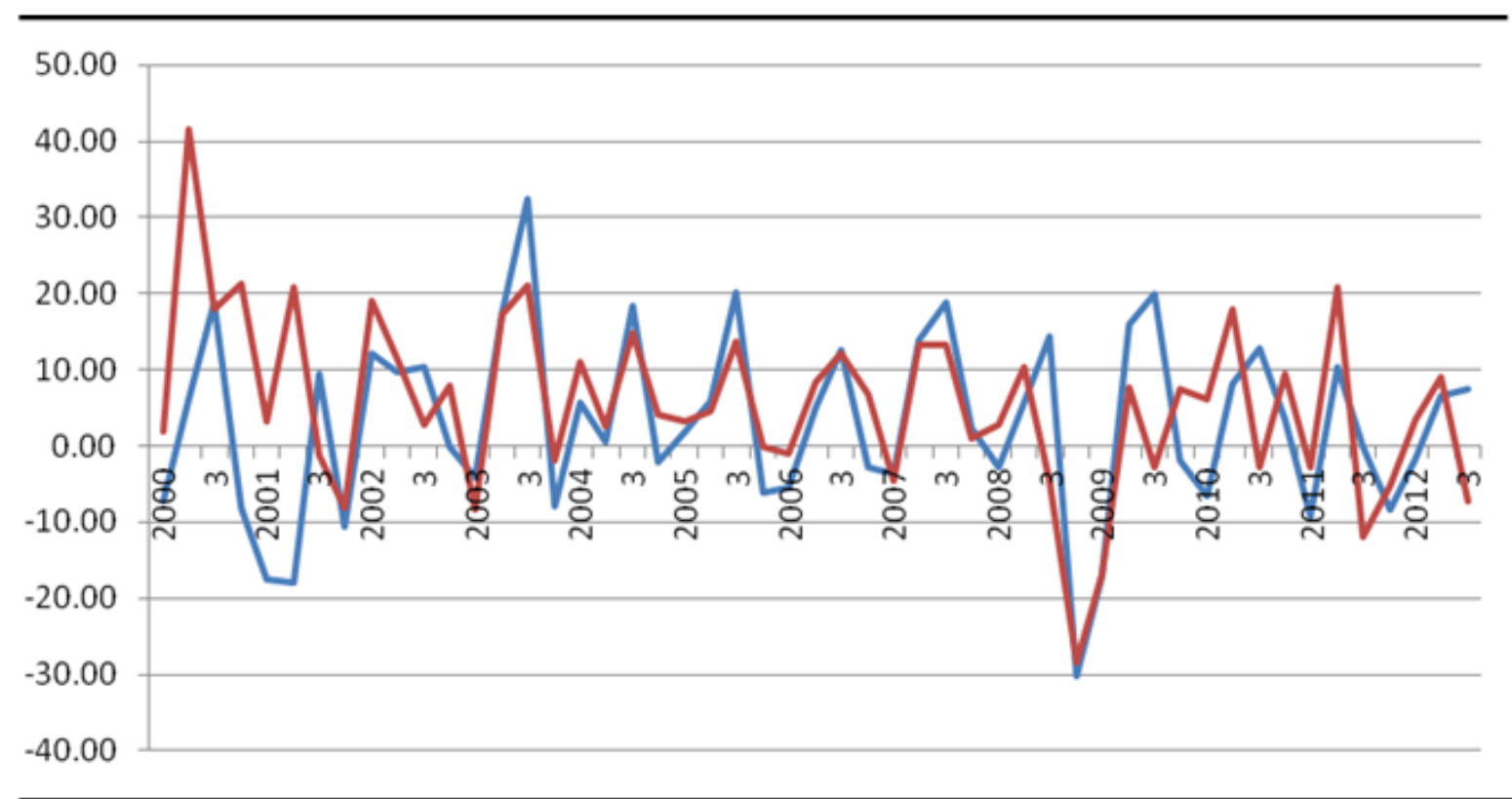

Source Data Set: CBRT, EDDS.

Interaction between the economic growth and the construction Industry:A Time Series Analysis On Turkey (2000-2012) 


\section{Appendix: 3}

Graph 2: GDP and The Construction Expenditure in The Gross Domestic Product-Total (Rate)

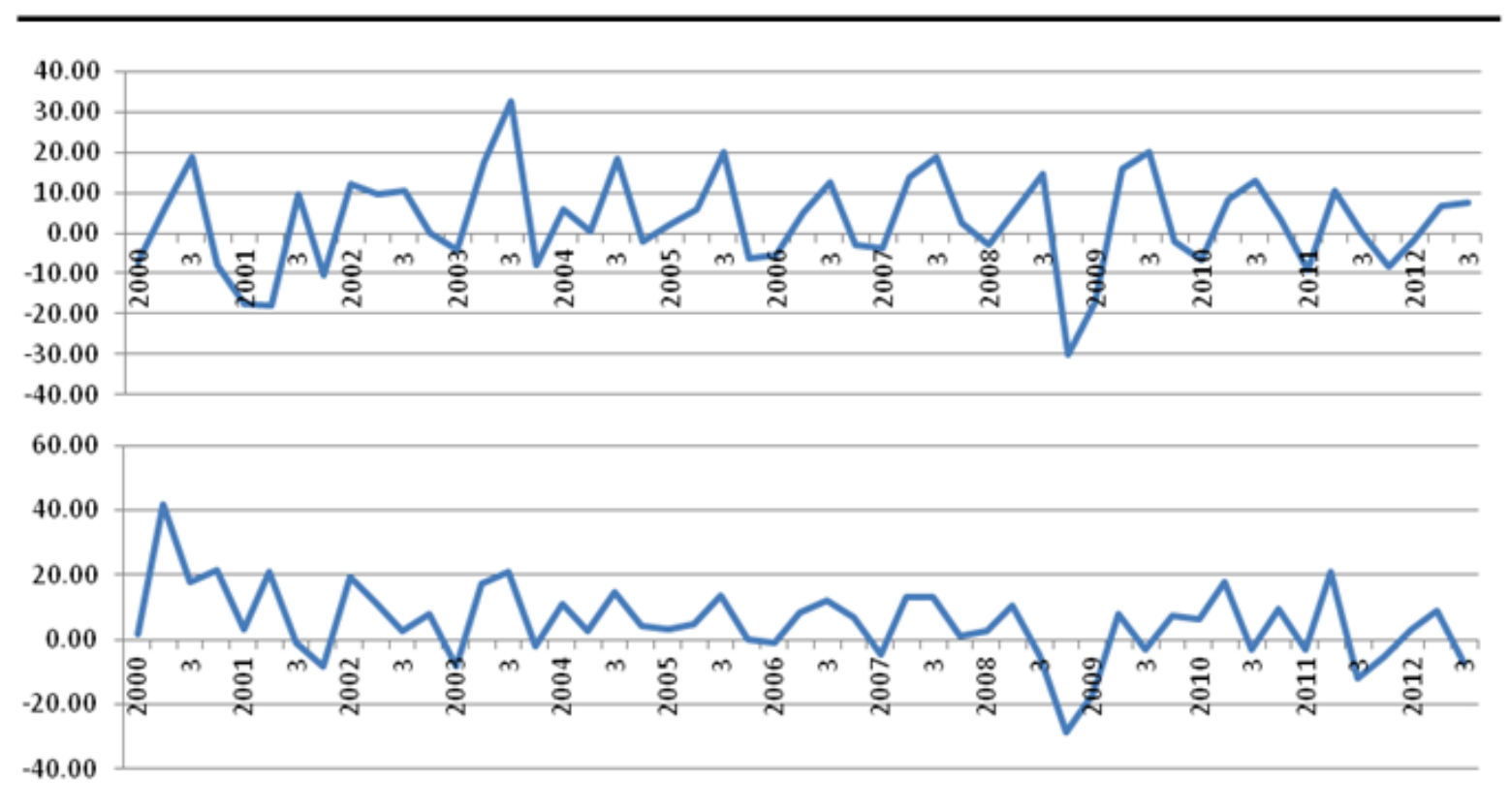

Source Data Set: CBRT, EDDS.

\section{Appendix: 4}

Table 1: Correlations (Level)

$$
\rho=\operatorname{Cor}(X, Y)=\frac{\operatorname{Orv}(X, Y)}{\sigma_{x} \sigma_{y}}=\frac{E\left[\left(X-\mu_{x}\right)\left(Y-\mu_{y}\right)\right]}{\sqrt{E\left[\left(X-\mu_{x}\right)^{2}\right] E\left[\left(Y-\mu_{y}\right)^{2}\right]}}
$$

\begin{tabular}{|c|c|c|c|c|c|c|c|c|}
\hline Variables & $\mathrm{gdp}$ & cpi & imkb100 & gfcf & cegdpps & cegdpprs & cegdptot & xtast \\
\hline gdp & 1 & -0.6838 & 0.93217 & 0.961938 & 0.963482 & 0.923413 & 0.967462 & 0.832401 \\
\hline cpi & & 1 & -0.57726 & -0.67688 & -0.61129 & -0.65828 & -0.66233 & -0.53048 \\
\hline imkb100 & & & 1 & 0.924436 & 0.895073 & 0.868131 & 0.90566 & 0.909787 \\
\hline gfcf & & & & 1 & 0.92259 & 0.977732 & 0.98906 & 0.854974 \\
\hline cegdpps & & & & & 1 & 0.865948 & 0.942173 & 0.755002 \\
\hline cegdpprs & & & & & & 1 & 0.983481 & 0.845018 \\
\hline cegdptot & & & & & & & 1 & 0.839478 \\
\hline xtast & & & & & & & & 1 \\
\hline
\end{tabular}

Source Data Set: CBRT, EDDS. (xtast, IMKB).

Interaction between the economic growth and the construction Industry:A Time Series Analysis On Turkey (2000-2012) 


\section{Appendix: $\mathbf{5}$}

Table 2: Correlations (First Differences)

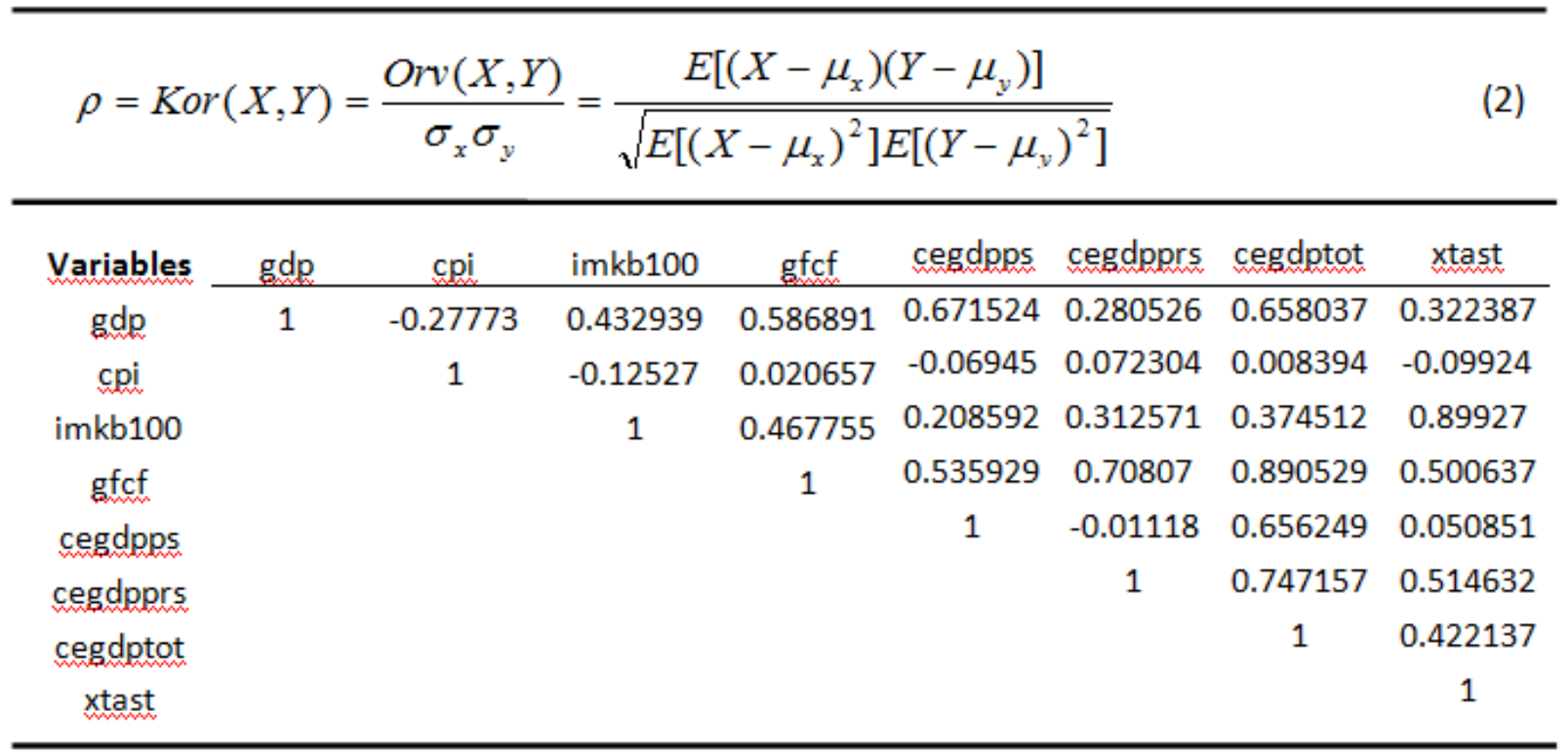

Source Data Set: CBRT, EDDS. (xtast, IMKB).

Interaction between the economic growth and the construction Industry:A Time Series Analysis On Turkey (2000-2012) 


\section{Appendix: 6}

Table 3: Augmented Dickev-Fuller (ADF) Unit-Root Test Estimation

$$
\Delta Y_{t}=\beta_{1}+\beta_{2} t+\beta_{3} Y_{t-1}+\alpha_{i} \sum^{m} \Delta Y_{t-i}+u_{t}
$$

\begin{tabular}{cccccc}
\hline Variables & ADF & $\Delta$ & Adj. $R^{2}$ & dw & Integrated \\
\cline { 2 - 6 } gdp & 0.372767 & -7.927132 & 0.588484 & 2.038116 & $\mathrm{I}(1)$ \\
cpi & -7.711515 & - & 0.797979 & 1.941704 & $\mathrm{I}(0)$ \\
imkb100 & -0.669617 & -4.775362 & 0.312361 & 1.915482 & $\mathrm{I}(1)$ \\
gfcf & -1.344247 & -5.779679 & 0.403020 & 1.979006 & $\mathrm{I}(1)$ \\
cegdpps & -0.542100 & -4.458922 & 0.812953 & 2.140767 & $\mathrm{I}(1)$ \\
cegdpprs & -1.557016 & -5.351236 & 0.365379 & 1.791165 & $\mathrm{I}(1)$ \\
cegdptot & -1.315302 & -6.224723 & 0.440215 & 1.950300 & $\mathrm{I}(1)$ \\
xtast & -1.726601 & -4.768993 & 0.311762 & 1.951683 & $(1)$ \\
\hline
\end{tabular}

Instructions: $\mathrm{R}^{2}$ and $\mathrm{dw}$ (Durbin-Watson) descriptive statistics belong to the integrated levels of the series. A series with an integration level I, I(1), becomes stationary after first differencing; I(0) series are stationary. As dw> $R^{2}$, spurious regression.

Source Data Set: CBRT, EDDS.

Interaction between the economic growth and the construction Industry:A Time Series Analysis On Turkey (2000-2012) 


\section{Appendix: 7}

Table 4: Granger Causality Test Estimation (First Differences)

$$
X_{t}=\sum_{i=1}^{n} \lambda_{i} X_{t-i}+\sum_{j=1}^{n} \Omega_{j} Y_{t-j}+u_{2 t}
$$

\begin{tabular}{cccc}
\hline The Direction of Causality & $\mathrm{f}$ & $\mathrm{p}$ & Result ( $\alpha=\% 5)$ \\
\cline { 2 - 4 } gfcf $\rightarrow$ gdp & 4.15186 & 0.02246 & Granger Causality Exist \\
imkb100 $\rightarrow$ gdp & 4.04066 & 0.02466 & Granger Causality Exist \\
cegdpps $\rightarrow$ gdp & 5.70704 & 0.00634 & Granger Causality Exist \\
gdp $\rightarrow$ cegdpps & 4.68833 & 0.01439 & Granger Causality Exist \\
cegdpprs $\rightarrow$ gdp & 3.34169 & 0.04477 & Granger Causality Exist \\
gdp $\rightarrow$ cegdpprs & 5.34270 & 0.00847 & Granger Causality Exist \\
xtast $\rightarrow$ gdp & 5.35560 & 0.00838 & Granger Causality Exist \\
cegdptot $\rightarrow$ gdp & 3.74846 & 0.03158 & Granger Causality Exist \\
imkb100 $\rightarrow$ gfcf & 3.90821 & 0.02757 & Granger Causality Exist \\
gfcf $\rightarrow$ cegdpps & 4.81536 & 0.01297 & Granger Causality Exist \\
gfcf $\rightarrow$ cegdpprs & 4.40366 & 0.01820 & Granger Causality Exist \\
gfcf $\rightarrow$ cegdptot & 5.28574 & 0.00886 & Granger Causality Exist \\
gfcf $\rightarrow$ cpi & 3.83800 & 0.02926 & Granger Causality Exist \\
xtast $\rightarrow$ gfcf & 3.90498 & 0.02765 & Granger Causality Exist \\
& & & \\
imkb100 $\rightarrow$ cegdpprs & 4.35820 & 0.01890 & Granger Causality Exist \\
imkb100 $\rightarrow$ cegdptot & 5.70908 & 0.00633 & Granger Causality Exist \\
cegdpprs $\rightarrow$ cegdpps & 4.13992 & 0.02268 & Granger Causality Exist \\
cegdptot $\rightarrow$ cegdpps & 4.13992 & 0.02268 & Granger Causality Exist \\
cegdpps $\rightarrow$ cegdptot & 3.87410 & 0.02838 & Granger Causality Exist \\
cegdpps $\rightarrow$ cpi & 5.70237 & 0.00636 & Granger Causality Exist \\
xtast $\rightarrow$ cegdpps & 3.33428 & 0.04506 & Granger Causality Exist \\
cegdpprs $\rightarrow$ cegdptot & 3.87410 & 0.02838 & Granger Causality Exist \\
xtast $\rightarrow$ cegdptot & 3.93905 & 0.02686 & \\
\hline
\end{tabular}

Instructions: $\mathrm{H}_{0}$ hypothesis; " $\mathrm{a} \rightarrow \mathrm{b}$ No Granger causality" or "a, is not the granger cause of $\mathrm{b}^{\prime}$. In case $\mathrm{p}>\boldsymbol{\alpha} \mathrm{H}_{9}$ hypothesis will be accepted. Otherwise $(p<\alpha) \mathrm{H}_{0}$ will be accepted. No other causality relation has been determined other than seven variables. Significance level is kept at $\% 5(0,05)$.

Source Data Set: CBRT, EDDS. (xtast, IMKB)

Interaction between the economic growth and the construction Industry:A Time Series Analysis On Turkey (2000-2012) 


\section{Appendix: 8}

Table 5: Regression Estimation 1

\begin{tabular}{|c|c|c|c|c|c|}
\hline$i m k b 100=b_{0}$ & ttast $+u$ & & & & \\
\hline Variables & Coefficient & Std. Error & t-Stat. & \multicolumn{2}{|l|}{ Other Statistics } \\
\hline$b_{0}$ & 822.5354 & 1.064956 & 14.24418 & Adj. $R^{2}$ & 0.804700 \\
\hline \multirow[t]{2}{*}{ xtast } & -0.001975 & 0.006748 & 2.926222 & F stat & 202.8966 \\
\hline & & & & $\mathrm{dw}$ & 1.599828 \\
\hline
\end{tabular}

Instructions: $n=51$. Adj. $R^{2}=0.804700$ and $d w$ (Durbin-Watson) $=1.599828\left(R^{2}<d w\right)$; regression is not a spurious one. Dependent variable can be explained by the independent variables with a rate of $\% 80.47$. Source Data Set: CBRT, EDDS.

\section{Appendix: 9}

Table 6: Regression Estimation 2

\begin{tabular}{crll|rr}
\hline$g f c f=b_{0}+b_{1} g d p+b_{2} c f i+b_{3} c e g d p p s+b_{4}$ cegdpprs $+u$ & & \\
\hline Variables & Coefficient & Std. Error & t-Stat. & Other Statistics & \\
\hline$b_{0}$ & 46293.41 & 272293.2 & 0.170013 & Adj. R & 0.780628 \\
gdp & 0.009806 & 0.017070 & 0.542683 & F stat & 44.59124 \\
cpi & 14492.05 & 49001.13 & 0.295749 & dw & 1.974409 \\
cegdpps & 1.572590 & 0.299415 & 5.252216 & & \\
cegdpprs & 1.902900 & 0.203557 & 9.348239 & & \\
\hline
\end{tabular}

Instructions: $n=51$. Adj. $R^{2}=0.780628$ and dw (Durbin-Watson) $=1.974409\left(R^{2}<\mathrm{dw}\right)$ regression is not a spurious one. Dependent variable can be explained by the independent variables with a rate of \%78.06. Source Data Set: CBRT, EDDS.

Interaction between the economic growth and the construction Industry:A Time Series Analysis On Turkey (2000-2012) 


\section{Appendix: 10}

Table 7 Regression Estimation 3

$$
g d p=b_{0}+b_{1} g f c f+b_{2} c e g d p p s+b_{3} c e g d p p r s+b_{4} x t a s t+u
$$

\begin{tabular}{|c|c|c|c|c|c|}
\hline Variables & Coefficient & Std. Error & t-Stat. & Other Statistics & \\
\hline$b_{0}$ & 721634.7 & 1633137 & 0.441870 & Adj. $R^{2}$ & 0.521584 \\
\hline gfcf & 0.035956 & 1.332003 & 0.026994 & F stat & 14.35532 \\
\hline cegdpps & 11.97129 & 2.850441 & 4.199805 & $\mathrm{Dw}$ & 2.705004 \\
\hline cegdpprs & 2.964152 & 2.969724 & 0.998124 & & \\
\hline xtast & 11485.06 & 7253.079 & 1.583474 & & \\
\hline
\end{tabular}

Instructions: $n=51$. Adj. $R^{2}=0.521584$ and $d w$ (Durbin-Watson) $=2.705004\left(R^{2}<d w\right)$ regression is not a spurious one. Dependent variable can be explained by the independent variables with a rate of \%52.15. Source Data Set: CBRT, EDDS.

\section{Appendix: 11}

Table 8: Regression Estimation 4

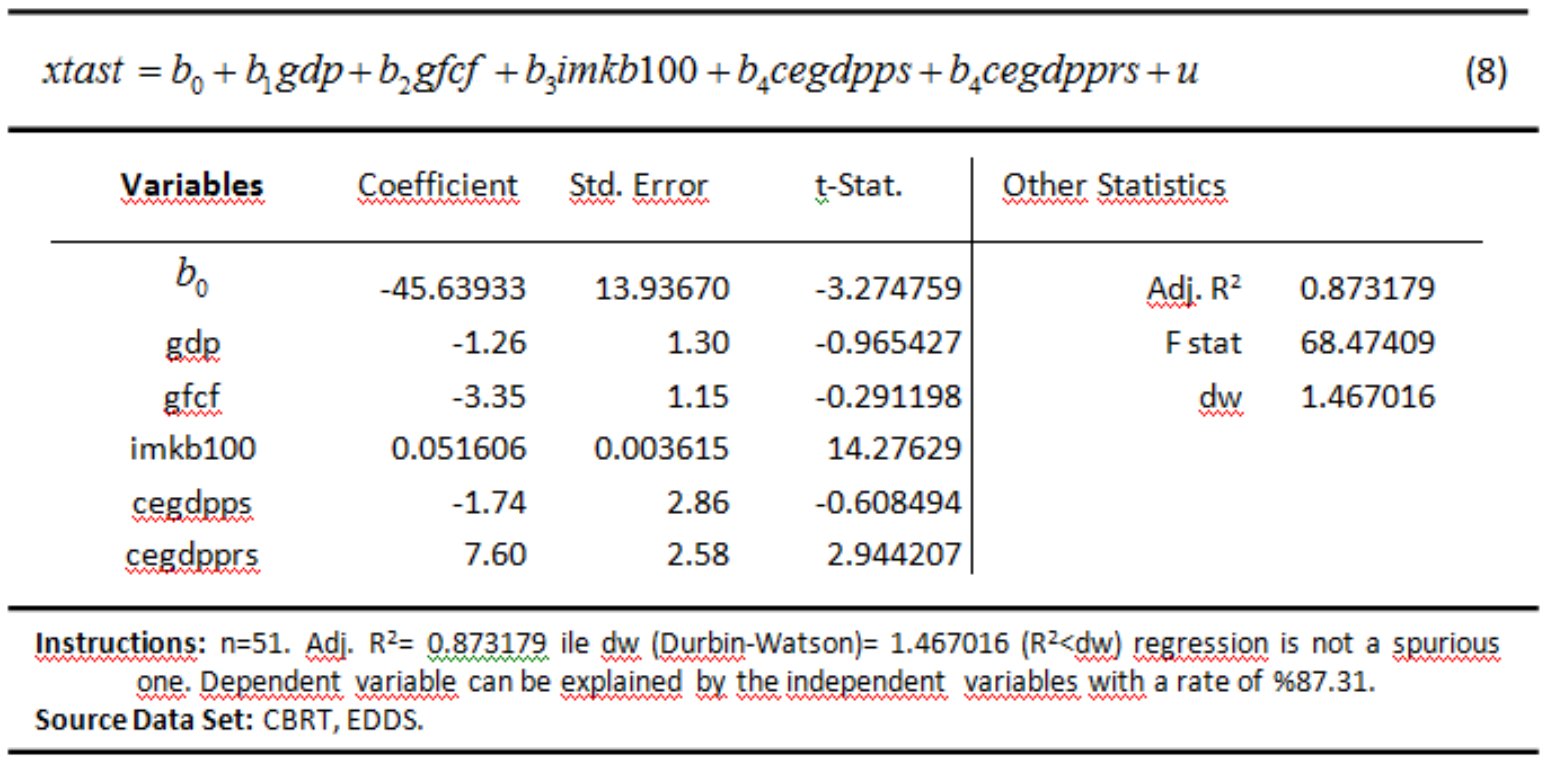

Interaction between the economic growth and the construction Industry:A Time Series Analysis On Turkey (2000-2012) 